\title{
"They called me a terrorist": Social and internalized stigma in Latino youth with type 1 diabetes
}

\section{BACKGROUND}

Diabetes-related stigma (DRS) globally affects patients' lives. Over a third of adolescents with type 1 diabetes (T1D) in Puerto Rico reported concerns of others knowing about their diabetes and about being different.

\section{PARTICIPANTS AND PROCEDURE}

We examined DRS among 65 T1D Latino youth (aged 12-17). During a depression-treatment study screening, they answered open-ended questions about diabetes-related concerns/difficulties and issues bothering them while interacting with peers, family, and healthcare professionals because of T1D. Using content analysis, we classified responses into Social stigma (SS), Internalized stigma (IS), and No stigma. Four SS and IS sub-categories were developed.

\section{RESULTS}

After coding, inter-rater reliability (Cohen's $\kappa)$ ranged from 0.73 to $1.00(p<.001)$. Forty-four youth $(67.69 \%)$ reported at least one DRS verbalization, and 25 reported more than one. Both SS and IS were identified in 32 (49.23\%) adolescents. Among SS experiences were: "they call me a junkie [because of insulin shots]"; "they call me a terrorist [because of the insulin pump]". IS verbalizations included: "I've never wanted to accept that I have T1D, so I don't practice good self-care"; "at times I do not feel the same as others". We found more stigma-related verbalizations among those from urban zones or larger families. DRS was related to increased depressive symptoms and risk of a depressive disorder. Peers were the main source of SS.

\section{CONCLUSIONS}

DRS was common, pervasive, and linked to depression. This study innovatively examines DRS in an exclusively T1D Latino and adolescent sample. Understanding its extent and nature is essential for developing interventions to address DRS.

\section{KEY WORDS}

diabetes; stigma; discrimination; depression; adolescents

Organization - 1: Ponce Health Science University, Ponce, Puerto Rico · 2: Ferkauf Graduate School of Psychology,

Yeshiva University, Bronx, New York, USA · 3: University of Puerto Rico, Río Piedras, Puerto Rico

AUthors' CONTRIBUtions - A: Study design - B: Data collection - C: Statistical analysis - D: Data interpretation .

E: Manuscript preparation · F: Literature search · G: Funds collection

corresponding Author - Eduardo Cumba-Avilés, Ph.D., University of Puerto Rico, Río Piedras Campus,

School of Social Sciences, Institute for Psychological Research (IPsi), 9 Ave. Universidad \#901, San Juan,

PR 00925-2509, e-mail: eduardo.cumba1@upr.edu

to CITE THIS ARTICLE - Crespo-Ramos, G., Cumba-Avilés, E., \& Quiles-Jiménez, M. (2018). "They called me a terrorist”:

Social and internalized stigma in Latino youth with type 1 diabetes. Health Psychology Report, 6(4), 307-320.

https://doi.org/10.5114/hpr.2018.80004

RECEIVED 02.06.2018 · REVIEWED 02.10.2018 · ACCEPTED 03.10.2018 · PUBLISHED 28.11.2018 


\section{BACKGROUND}

Diabetes is among the most prevalent and burdensome chronic physical illnesses (CPI). Its global agestandardized prevalence increased from $4.30 \%$ in 1980 to $9.00 \%$ in 2014 in men, and from $5.00 \%$ to $7.90 \%$ in women, with a total worldwide increase from 108 million to 422 million (NCD Risk Factor Collaboration, 2016). Since 1996, Puerto Rico has had the highest prevalence of diabetes in the United States and its territories (Centers for Disease Control and Prevention, 2016). Diabetes is associated with many comorbid problems (Llorente \& Malphrus, 2007; Piette $\&$ Kerr, 2006) and high mortality rates (Stokes \& Preston, 2017). Although policy makers and healthcare professionals recognize it as a major global health concern, factors behind prejudices about people with diabetes still need to be addressed (Schabert, Browne, Mosely, \& Speight, 2013).

People living with a CPI may internalize, experience, and anticipate stigma - social devaluation or discredit - due to their illness (Goffman, 1963). Stigmatized persons are classified as not quite human, suffer various forms of discrimination and, as a result, their life opportunities are reduced (Goffman, 1963). Two main types of stigma have been identified: internalized stigma, also known as felt or self-stigma, and social or enacted stigma (Scambler, 1998). Internalized stigma (IS) refers to real or imagined fear of societal attitudes, including shame and expectation of discrimination that prevents people from disclosing their status or sharing their experiences (Gray, 2002; Jacoby, 1994). IS could withhold someone from situations (e.g., practicing self-care in public), interactions (e.g., making new friends), roles (e.g., being a leader) or help-seeking to prevent stigmatization; it could even lead people to endorse negative stereotypes about the group to which they belong. Social stigma (SS) refers to the actual experience of discrimination, blaming or judgment, when labeled people are unfairly treated by others or are denied opportunities available to non-labeled people (Gray, 2002; Jacoby, 1994).

Stigma may be a source of further complications, barriers, and burden for patients with a CPI. For instance, IS and SS experienced from healthcare workers are recognized as barriers to treatment seeking, and as factors that contribute to a decrease in quality of life in CPI patients (Earnshaw \& Quinn, 2012). People diagnosed with a CPI report experiencing social rejection, workplace discrimination and poor healthcare because of their illness (Lee, Lee, Chiu, \& Kleinman, 2005; Sayles, Ryan, Silver, Sarkisian, \& Cunningham, 2007). Besides interactions with healthcare providers and coworkers, actual or expected stigmatization affects relationships with family, friends, and teachers (Browne, Ventura, Mosely, \& Speight, 2013; Earnshaw, 2011). This has been observed in people with either type 1 (T1D) or type 2 diabetes (T2D) (Browne et al., 2013;
Browne, Ventura, Mosely, \& Speight, 2014; Lee, Lim, \& Koh, 2015; Vaz, Travasso, \& Vaz, 2016; Willig, Richardson, Agne, \& Cherrington, 2014). People identified as having a CPI, such as diabetes, may be discouraged from being tested, accessing medical services/medications, and disclosing their health status to family and friends (Elissa, Bratt, Axelsson, Khatib, \& Sparud-Lundin, 2017; Sayles et al., 2007; Willig et al., 2014). Current policy may also contribute to social perceptions of people with diabetes as morally inadequate or deserving to be blamed for their condition (Bossy, Knutsen, Rogers, \& Foss, 2017). In fact, SS is among the many costs of having diabetes (Schabert et al., 2013).

The proportion of people with diabetes who have experienced stigma or believe that diabetes comes with stigma varies across samples and data collection methods. Using qualitative methods or non-structured questionnaires, reports of actual SS have ranged from $12.00 \%$ (Lee et al., 2015) to $51.85 \%$ (Browne et al., 2014) in adults. In a large online survey, when patients were asked if they agreed that diabetes comes with SS, $52.00 \%$ of those with T2D and $76.00 \%$ of those with T1D agreed (Liu et al., 2017). Parents of T1D children agreed the most (83.00\%), and the lowest rate $(49.00 \%)$ was for people with T2D who did not use insulin. In a sample of T2D adults, about $60.00 \%$ affirmed that SS was associated with the condition (Browne et al., 2013). Another 24.00\% believed there was no stigma, but described evidence of it during their interviews. In small samples of T1D adults and young adults, as many as $92.59 \%$ (Browne et al., 2014) and $100.00 \%$ (Abdoli, Irani, Parvizi, Fatemi, \& Amini, 2013b), respectively, acknowledged there is such a thing as diabetes-related stigma (DRS).

In some studies, researchers assessed the occurrence of DRS experiences by providing participants with specific examples to choose from. Gredig and BartelsenRaemy (2017) found that $68.50 \%$ of their sample (aged 16 to 96 ) reported having been discriminated against because of their condition (T1D or T2D). About $84.40 \%$ reported having heard at least one of the 26 negative stereotypical attributions about diabetes included in the questionnaire. Knowing of someone who gives strange looks to people with diabetes when using insulin in public (55.20\%) and who believes they are to blame for their illness (39.47\%), have a terrible disease (42.73\%), are "lost souls" (37.94\%), or deserve pity (37.74\%), were among the most endorsed items. Liu et al. (2017) asked those who believed that diabetes comes with SS if they thought that society perceived people with diabetes as having a character flaw or fault, as showing a personal responsibility failure, and/or as being a burden on the health care system. About $81.00 \%, 52.00 \%$, and $65.00 \%$ of them, respectively, agreed with each question. Furthermore, in a study by Lee et al. (2005), around $22.00 \%$ and $28.00 \%$ of participants with diabetes reported that they deliberately concealed illness from friends and from coworkers/schoolmates, respectively. 
The experience of DRS has many faces. In studies reviewed, SS included social judgment, being blamed and shamed by others for their condition, being associated with negative stereotypes, and experiencing exclusion, discrimination, rejection, or restriction of opportunities (Browne et al., 2013, 2014). A logical consequence of exposure to SS is to show IS. Among the many forms of IS are to feel different/imperfect, to feel deprived of a normal life, or to assume a negative self-image/identity, usually due to internalized negative social stereotypes (Abdoli, Abazari, \& Mardanian, 2013a; Della, Ashlock, \& Basta, 2011; Nishio $\&$ Chujo, 2017). Some may develop a negative "relationship" with the disease, which can manifest in denial or difficulties accepting diabetes or some aspect of its self-care, such as insulin use (Adams \& Carter, 2010; Kato et al., 2016; Nishio \& Chujo, 2017). Other instances of IS among people with diabetes may relate to limiting social behavior/participation, or avoiding to disclose their health status, mainly because of the shame associated with their condition or with practicing self-care in public, and the assumption that they will be the target of social judgment or labeling (Alzubaidi, Mc Mamara, Chapman, Stevenson, \& Marriott, 2015; Earnshaw, 2011; Kato et al., 2016; Tak-Ying Shiu, Kwan, \& Wong, 2003).

Few studies on DRS have focused on children. In the mid-20th century, Fischer (1948) identified stigma among the factors responsible for emotional disturbances in children with diabetes. Thirty-five years ago, the psychological stigma of diabetes was found to be higher among children of mothers from lower socioeconomic status (Banion, Miles, \& Carter, 1983). Youths' perceived stigma has been recognized as a barrier to access the support they need to manage the emotional and behavioral challenges of T1D (Clarke et al., 2015) and to their adherence to the medical regimen (Mulvaney et al., 2011). Many youths report that T1D makes them feel less normal, reflecting their difficult to incorporate diabetes into their identity. The frustration aroused by disruptions to everyday life and the negative reactions from peers affect self-care and reduce the willingness to disclose their health status (Commissariat, Kenowitz, Trast, Heptulla, \& Gonzalez, 2016; Marshall, Carter, Rose, \& Brotherton, 2009; Rankin, Harden, Jepson, \& Lawton, 2017). Among parents of T1D children, about $39.00 \%$ strongly agreed that their child had experienced guilt, shame, embarrassment, isolation or blame because of DRS (Folias et al., 2014). In the words of Lambert and Keogh (2015), children with a CPI "felt different physically and socially and they grappled constantly with balancing the dilemma of feeling and acting normal or feeling, being and revealing difference" (p. 63).

Researchers have documented the stigma of pediatric diabetes in different countries. In Palestine, children and their parents described how stigmatization and social constraints impacted their daily life as a re- sult of fear of disclosing the disease, which could affect their social status (Elissa et al., 2017). Stigma has also been identified among the factors affecting the quality of life of T1D youth and their families in Zambia (Hapunda, Abubakar, van de Vijver, \& Pouwer, 2015), Tanzania (Muze \& Majaliwa, 2015), and Tajikistan (Haugvik, Beran, Klassen, Hussain, \& Haaland, 2017). Although we did not find a study that examined the prevalence of DRS in a sample composed exclusively of adolescents with T1D, a large-scale study recently examined this issue in Canadian youth aged 14 to 24 . The results suggest a stigma prevalence of $65.50 \%$ among the whole sample and of $61.20 \%$ among the 14 to 18 years old age group (Brazeau et al., 2018). Although DRS is thought to be common among Latinos (McQuillan, 2014), we found no published study focused on the prevalence and nature of DRS among adult or children from this ethnic group.

Data from 101 T1D youth from Puerto Rico (aged 8 to 17 years) showed a significant link among youth diabetes-related concerns, low perceived social support, and hopelessness (Rosselló \& MaysonetGuzmán, 2006). About $35.00 \%$ were concerned about others knowing they had T1D and $38.14 \%$ worried about being different. Such results are consistent with research reflecting T1D children as struggling to reveal their health status to avoid the stigma of feeling and being treated as less "normal" than peers (Commissariat et al., 2016).

Consequences of stigma span many life domains, including relationships and social identity, behavioral management of diabetes, BMI, rates of hospitalization, glycemic control, and emotional well-being (Browne et al., 2013, 2014; Lee et al., 2015; Liu et al., 2017). Depression was positively related to self-stigma in patients with T2D (Kato, Takada, \& Hashimoto, 2014). Among people with T1D or T2D (aged 16 to 96), those with higher perceived stigma reported more severe depressive symptoms, which in turn predicted a lower quality of life (Gredig \& Bartelsen-Raemy, 2017). As stigma is a barrier to treatment seeking and self-management, even among Latinos with diabetes (Cabassa, Hansen, Palinkas, \& Ell, 2008; Hansen \& Cabassa, 2012; Weiler \& Crist, 2009), and has a negative impact on many areas, assessing DRS early after diagnosis and then periodically could help to identify patients in need of emotional or social support. This may contribute to prevention/amelioration of consequences associated with these experiences, which might not only help to reduce the development or severity of diabetic complications and the cost of diabetes care, but also increase the quality of life of patients. Due to their search for identity and susceptibility to negative evaluation, youth may be more vulnerable to stigma and its adverse impact when presenting a CPI, including the development or worsening of depression (O’Donohue \& Tolle, 2009). However, few studies have documented the extent and nature of this problem
Stigma in Latino youth with $T 1 D$ 
Gladys CrespoRamos,

Eduardo CumbaAvilés, Martha QuilesJiménez among T1D youth, and no study has examined DRS and its relationship with depression among Latinos.

In the current study, we aimed to extend current knowledge on DRS among youth by exploring its prevalence and nature in a sample of T1D Latino adolescents, and examining its relationship with sociodemographic variables and depressive symptoms. We also explored which potential stigma source (peers, family or professionals) was more common in youth responses. We expected that at least $35.00 \%$ of youth would report a lifetime DRS experience, and that a history of DRS (particularly social stigma) would be associated with higher depressive symptoms and higher odds for diagnosis of a current depressive disorder. We thought that the main themes reflected in youths' DRS reports would be similar to those reported in previous research. Finally, we expected peers to be the most common stigma source reported.

\section{PARTICIPANTS AND PROCEDURE}

\section{PARTICIPANTS}

Participants were 65 T1D adolescents (36 girls) from Puerto Rico aged 12-17 years $(M=15.05, S D=1.68)$, who attended the screening assessment for a depression treatment study. Previously, their main caregivers had completed a request for participation (RFP) form in which they reported that their child presented significant depressive symptoms (i.e., at least three DSM symptoms in the previous two weeks or more, one of which must be depressed mood or anhedonia). Psychotic symptoms, history of bipolar disorder, last-year substance dependence/abuse, and imminent suicide risk were among the exclusion criteria. A more detailed description of the main study is presented elsewhere (Cumba-Avilés \& Sáez-Santiago, 2016). This report is based on secondary data analyses from that sample.

Most caregivers (93.85\%) and youths (96.92\%) were Puerto Ricans; the rest were from other Latino groups. About $64.62 \%$ (42) of adolescents attended public schools. The same proportion lived in urban zones, and 43.08\% (28) resided in the San Juan Metro Area. Primary caregivers were mostly (81.54\%) women. Their ages ranged from 32 to 58 years $(M=43.34$, $S D=6.42)$, and their mean education was 14.75 $(S D=2.34)$ years. Around $55.38 \%$ (36) had full-time employments and $9.23 \%$ (6) had part-time jobs. As reported in the socio-demographic data form, most participants $(75.38 \%$ ) belonged to families of mid-low or low socio-economic status. The mean household size was $3.94(S D=0.93)$ members with a range of 2 to 7 members.

Mean $\mathrm{HbA}_{1 \mathrm{c}}$ value, a test of the average blood sugar levels in the past 3 months, was $9.03(S D=2.10$, range from 5.76 to 17.70$)$. To obtain these data, we asked caregivers for a copy of their child's last test results. Only 14 youth were on insulin pump treatment. Mean score in the Children's Depression Inventory was 18.28 , suggesting that most had moderate or severe depressive symptoms. Mean time since child's T1D diagnosis was 6 years.

\section{MEASURES}

Children's Depression Inventory (CDI). This is a selfreport measure of depressive symptoms in youth aged 7-17 years (Kovacs, 2001). Its reliability in this sample was .84 .

Diagnostic Interview Schedule for Children-IV (DISC-IV) - Parent Version. This is a structured interview used to assess DSM diagnostic criteria for several mental disorders in youth (Shaffer, Lucas, Dulcan, \& Schwab-Stone, 2000). Its Spanish Parent Version has shown adequate reliability in samples of Latino caregivers from Puerto Rico (Bravo et al., 2001). Caregivers completed the Depression module during the screening interview.

Adolescent Diabetes-Related Experiences Worksheet $(A D R E W)$. This form included five self-report openended questions related to concerns and difficulties about living with diabetes, as well as situations or issues that had bothered youth while interacting with peers, family, and healthcare professionals because of their illness. We developed questions aiming to capture both self-referenced evaluations and reports of difficult social experiences that might be of particular interest for planning treatment according to adolescents' needs.

\section{PROCEDURE}

We disseminated information about the study in T1D clinics, newspapers, and the radio and by distributing printed materials. We recruited youths through summer camps, educational or recreational activities, and through referrals from endocrinologists, school personnel, and other participants. Upon initial phone contact, we provided additional information about the study. If interested, caregivers completed RFP forms. Research staff evaluated forms for eligibility. If no exclusion criteria were present, an appointment was coordinated for a screening assessment. Both the adolescent and a primary caregiver participated in this phase. Participants in the study were youth (a) aged 12-17 years, (b) diagnosed with T1D, (c) referred for depressive symptomatology, (d) and with at least one caregiver, aged 21 years or older, who was available to bring him/her to the study's visits. Study procedures were in accordance with the Helsinki Declaration of 1975, as revised in 2000. Prior to data 
collection, participants signed informed consent/ assent forms. Trained graduate students conducted assessments in Spanish between February 2013 and April 2015. Their length was about two hours. Caregivers completed a socio-demographic data form, and provided other health history and clinical information regarding youth depression and T1D. Youth completed the CDI and other measures of depression-related symptoms (not reported here), as well as the ADREW. Responses provided by youth on the ADREW were clarified by evaluators as needed to assure data precision. The IRB offices from both the UPR-Río Piedras (1112-005) and UPR-Medical Science Campus (A9530112) approved the study.

\section{DATA ANALYSES}

Using thematic content analysis, we evaluated youth responses in the ADREW and classified them into three main general categories: Social stigma (SS), Internalized stigma (IS), and No stigma. The first two general categories were divided into four subcategories each, as identified by the first two authors after studying recurrent themes. We present subcategories' names and definitions in the Results section. The first two authors accorded definitions for each general and specific category and developed coding rules. We obtained final definitions and coding rules after two revisions. A master key of codes was achieved through codifications by the first two authors. Disagreements were resolved by consensus. The definitions, coding rules, and a master copy of the qualitative data were then delivered to an external rater for coding. The master key of codes as well as codes provided by the external rater were entered into a database to estimate overall agreement $(\%)$ and the agreement level that was not due to chance. For the latter, we used Cohen's $\kappa$ coefficient, providing a $95.00 \%$ confidence interval (CI).

We conducted statistical analyses with SPSS 22.0. Using frequencies and percentages, we estimated the prevalence of at least one stigma experience, at least one SS, at least one IS, at least one of both (SS and IS), or at least two stigma experiences of any kind. We also calculated the total number of stigma verbalizations, and the amount per general and specific categories. Using $t$-tests for continuous variables and chi-square tests for categorical ones $(p<.05)$, we made comparisons of these variables, considering groups based on socio-demographic variables. Using Pearson correlations, we estimated the association between current self-reported depressive symptoms and the number of IS, SS and total stigma experiences. Finally, with the chi-square test and odds ratios (OR), we examined the association between a history of DRS and being diagnosed with a current depressive disorder.

\section{RESULTS}

\section{PREVALENCE OF STIGMA EXPERIENCES AND RELATIONSHIP WITH DEMOGRAPHIC VARIABLES}

Forty-four youths $(67.69 \%)$ provided at least one verbalization that reflected DRS, with a total of 96 distinct verbalizations. About $38.46 \%$ reported more than one experience. Twelve gave responses reflecting only SS or only IS, and 20 reported experiences of both types. Thus, the prevalence of IS and the rate of SS were both $49.23 \%$ (32). The number of SS experiences ranged from 0 to $7(M=0.86, S D=1.22)$. This range was from 0 to $4(M=0.62, S D=0.76)$ and from 0 to $8(M=1.48$, $S D=1.61)$ for IS and for total stigma experiences, respectively.

We analyzed the mean number of stigma experiences by adolescent's sex, age group, type of school attended, as well as by caregivers' job status (currently employed at a full-time basis or not), family composition (single-parent vs. two-parent homes), socioeconomic status, and zone of residence. Only the latter variable showed significant differences among subgroups $[t(62.90)=-2.13, p=.037, d=.47]$, with adolescents living in urban zones $(n=42, M=1.74, S D=1.84)$ presenting a higher mean number of total stigma experiences than those living in rural zones $(n=23, M=1.00$, $S D=0.95)$. We did not find any difference in the proportion of cases with any stigma, SS, IS, both types of stigma, or two or more experiences. Mean number of DRS experiences was unrelated to time since T1D diagnosis, caregivers' age or education. However, those who reported two or more stigma experiences of any kind lived in larger families $(n=25, M=4.28$, $S D=1.06)$ than those who did not $[n=40, M=3.73$, $S D=0.78, t(63)=2.42, p=.018, d=.62]$. The effect sizes (Cohen's $d$ ) for $t$-test group comparisons were estimated by dividing the mean difference by the pooled $S D$.

\section{RELATIONSHIP BETWEEN DRS AND DEPRESSION}

CDI total scores were significantly associated with the total number of DRS experiences $(r=.29, p=.009)$ and SS events $(r=.30, p=.009)$, but not IS reports $(r=.14, p=.130)$. Scores on the Anhedonia subscale of the CDI, on the other hand, were related to the number of SS $(r=.28, p=.012)$, IS $(r=.23, p=.034)$ and total $(r=.32, p=.005)$ stigma experiences. As shown in Table 1, we found a significant association between having at least one experience of SS and being diagnosed with a depressive disorder (DD) whose most recent episode was still active in the two weeks before intake. The odds for a current DD were 3.54 times higher among those with a history of SS than among those without such history. Also, there was a sig-
Stigma in Latino youth with $T 1 D$ 
Gladys CrespoRamos,

Eduardo CumbaAvilés,

Martha QuilesJiménez nificant bivariate association between having experiences of both types of DRS (SS and IS) and meeting criteria for a DD, and between the latter and having a history of any two or more DRS experiences. The odds ratio in both cases was more than five times and 4.50 times higher, respectively, among those who met the stigma criteria examined. In the three instances mentioned above, odds ratio values remained significant after controlling for zone of residence and household size. No significant associations were observed for the categories Any stigma or Internalized stigma.

\section{RATES OF OCCURRENCE OF SPECIFIC STIGMA CATEGORIES AND EXTERNAL RATER'S RELIABILITY}

In Table 2 we summarized the frequency of occurrence for categories used to code youth responses in the ADREW. Fifty-six of the 96 stigma experiences reported $(58.33 \%)$ were coded as SS and 40 as IS. These 96 were the $29.72 \%$ of the 323 units available for coding. Feeling Different/Self-Stereotyping was the most frequent form of IS, accounting for $19.79 \%$ of all DRS verbalizations and $47.50 \%$ of IS events. Micro-Aggressions were the most common form of
SS and of any type of stigma, and accounted for $28.12 \%$ of all DRS codes and almost half of SS events. The least common form of DRS was the IS category called Non-Disclosure, followed by the SS category known as Negative Social Stereotypes. As a negative stereotype underlies most SS events, we coded this category only if the elements to code other SS categories were not met.

Two independent raters coded all units. When examining ratings with general categories (3) as options, their overall raw agreement was $94.12 \%$, with a $\kappa$ of $.87(95 \% \mathrm{CI}=.82-.93)$. Yet, if the specific categories (i.e. four SS categories, four IS categories, and No stigma) were used (as in a $9 \times 9$ crosstab), agreement of $92.26 \%$ was obtained, with a $\kappa$ of .84 (.79-.90). Global raw agreement with final key codes ranged from $95.05 \%$ (rater 2) to $99.07 \%$ (rater 1) when using three options and from $93.50 \%$ (rater 2) to $98.76 \%$ (rater 1) if using nine specific categories. These agreements corresponded to $\kappa$ values that ranged from .89 (rater 2) to .98 (rater 1) in the first case and from .87 (rater 2) to .97 (rater 1) in the second. We also estimated $\kappa$ for any separate category, using standard Yes/No ratings $(2 \times 2$ crosstab) applied to all units (see Table 2). The $\kappa$ values for raters 1 and 2 ranged from 0.73 to $1.00(p<.001)$. In Table 2 , we also show

Table 1

Association between a history of DRS and a current diagnosis of a depressive disorder

\begin{tabular}{|c|c|c|c|c|}
\hline Stigma variable & $\begin{array}{c}\text { Current DD } \\
\text { diagnosis } \\
(n=25)\end{array}$ & $\begin{array}{c}\text { No DD } \\
\text { diagnosis } \\
(n=40)\end{array}$ & $\chi^{2}$ & $\begin{array}{l}\text { OR/AOR } \\
(95 \% \mathrm{CI})\end{array}$ \\
\hline \multicolumn{5}{|l|}{ Any stigma } \\
\hline Yes $(n=44)$ & $40.90 \%(18)$ & $59.10 \%(26)$ & 0.56 & $1.38(0.47-4.11)$ \\
\hline No $(n=21)$ & $33.33 \%(7)$ & $66.67 \%(14)$ & & $1.36(0.45-4.14)$ \\
\hline \multicolumn{5}{|l|}{ Social stigma } \\
\hline Yes $(n=32)$ & $53.10 \%(17)$ & $46.90 \%(15)$ & $5.73^{*}$ & $3.54^{*}(1.23-10.19)$ \\
\hline No $(n=33)$ & $24.20 \%(8)$ & $75.80 \%(25)$ & & $3.80^{*}(1.27-11.35)$ \\
\hline \multicolumn{5}{|c|}{ Internalized stigma } \\
\hline Yes $(n=32)$ & $43.80 \%(14)$ & $56.30 \%(18)$ & 0.74 & $1.56(0.57-4.25)$ \\
\hline No $(n=33)$ & $33.33 \%(11)$ & $66.67 \%(22)$ & & $1.51(0.54-4.21)$ \\
\hline \multicolumn{5}{|l|}{ Both types } \\
\hline Yes $(n=20)$ & $65.00 \%(13)$ & $35.00 \%(7)$ & $8.60^{* *}$ & $5.11^{* *}(1.65-15.84)$ \\
\hline No $(n=45)$ & $26.70 \%(12)$ & $73.30 \%(33)$ & & $5.34^{* *}(1.66-17.19)$ \\
\hline \multicolumn{5}{|c|}{$\geq$ Two experiences } \\
\hline Yes $(n=25)$ & $60.00 \%(15)$ & $40.00 \%(10)$ & $7.96^{* *}$ & $4.50^{* *}(1.54-13.17)$ \\
\hline No $(n=40)$ & $25.00 \%(10)$ & $75.00 \%(30)$ & & $5.31^{* *}(1.62-17.39)$ \\
\hline
\end{tabular}

Note. Percentages are based on the proportion of adolescents with stigma that presented a current (past two weeks) depressive disorder as reported by caregivers. For each stigma-related variable, we presented first the crude odds ratio value and then (below) the adjusted odds ratio, controlling for zone of residence and household size. DD - depressive disorder; DRS - diabetes-related stigma; OR - odds ratio (crude); AOR - adjusted odds ratio. ${ }^{*} p<.05,{ }^{* *} p<.01$. 
raw percentages and $\kappa$ values for separate categories when testing the agreement that each rater had with key codes. We present here qualitative results based on those key codes.

\section{EXAMPLES OF EXPERIENCES OF SOCIAL STIGMA}

The development of SS categories was influenced by Browne and colleagues (2013). Below, we provide examples within each sub-category of SS as reflected on the ADREW.

Negative Social Stereotypes. It refers to statements in which the participant affirms that others possess a distorted or simplified concept about diabetes (including its origins, nature, and self-care), which is expressed through words or actions reflecting prejudice or misinformation.

(They worry) if it (diabetes) can be spread by contact or if I can die. (Boy A, 12)
That being in the line of the school diner, at times I have to go upfront and other students protest without knowing my rights, which I can use without abuse. (Boy B, 15)

Blame/fudge and Shame. It includes instances of been accused/reprimanded because of T1D or difficulties achieving self-care goals, when others point to T1D as a cause of misfortunes, or convey attitudes/ comments that embarrass the person, make him/her feel worthless, or imply that he/she lies about selfcare compliance or lacks the knowledge to perform those tasks.

...they can't see me with some food in my hands without saying that I am eating secretly and stuff like that. (Boy C, 15)

My brother always blames diabetes for everything. (Girl A, 13)

They (my family) nag me too much and treat me as if I don't know about my illness. (Girl B, 13)

Exclusion/Rejection/Discrimination. It refers to instances in which adolescents claim that others avoid

Table 2

Experiences of stigma in adolescents and reliability of raters' codes by general and specific categories

\begin{tabular}{|c|c|c|c|c|c|c|c|c|c|}
\hline \multirow[b]{2}{*}{$\begin{array}{l}\text { Diabetes- } \\
\text { related } \\
\text { stigma } \\
\text { categories }\end{array}$} & \multicolumn{3}{|c|}{$\begin{array}{l}\text { Proportion } \\
\text { of occurrence }\end{array}$} & \multicolumn{2}{|c|}{ Raters 1 vs. 2} & \multicolumn{2}{|c|}{ Rater 1 vs. Key codes } & \multicolumn{2}{|c|}{ Rater 2 vs. Key codes } \\
\hline & $f$ & $\begin{array}{l}\text { Within } \\
\text { global } \\
\text { class }\end{array}$ & $\begin{array}{c}\text { Within } \\
\text { any } \\
\text { stigma }\end{array}$ & $\begin{array}{l}\text { Agree } \\
\text { raw } \%\end{array}$ & $\begin{array}{l}\text { Cohen's к } \\
(95 \% \mathrm{Cl})\end{array}$ & $\begin{array}{l}\text { Agree } \\
\text { raw } \%\end{array}$ & $\begin{array}{c}\text { Cohen's к } \\
(95 \% \mathrm{Cl})\end{array}$ & $\begin{array}{l}\text { Agree } \\
\text { raw } \%\end{array}$ & $\begin{array}{l}\text { Cohen's к } \\
(95 \% \mathrm{Cl})\end{array}$ \\
\hline $\begin{array}{l}\text { Social } \\
\text { stigma }\end{array}$ & 56 & - & $58.33 \%$ & $97.83 \%$ & $0.93(0.87-0.98)$ & $99.69 \%$ & $0.99(0.97-1.00)$ & $98.14 \%$ & $0.94(0.88-0.99)$ \\
\hline $\begin{array}{l}\text { Negative } \\
\text { SST }\end{array}$ & 4 & $7.14 \%$ & $4.17 \%$ & $99.38 \%$ & $0.80(0.52-1.00)$ & $100.00 \%$ & $1.00(\mathrm{~N} / \mathrm{A})$ & $99.38 \%$ & $0.80(0.52-1.00)$ \\
\hline $\begin{array}{l}\text { Blame/ } \\
\text { shame }\end{array}$ & 11 & $19.64 \%$ & $11.46 \%$ & $98.45 \%$ & $0.73(0.50-0.96)$ & $100.00 \%$ & $1.00(\mathrm{~N} / \mathrm{A})$ & $98.45 \%$ & $0.73(0.50-0.96)$ \\
\hline$E / R / D$ & 14 & $25.00 \%$ & $14.58 \%$ & $98.45 \%$ & $0.81(0.64-0.98)$ & $99.38 \%$ & $0.93(0.82-1.00)$ & $99.07 \%$ & $0.88(0.75-1.00)$ \\
\hline MA & 27 & $48.21 \%$ & $28.12 \%$ & $97.83 \%$ & $0.87(0.77-0.97)$ & $99.69 \%$ & $0.98(0.94-1.00)$ & $98.14 \%$ & $0.89(0.79-0.98)$ \\
\hline Self-stigma & 40 & - & $41.67 \%$ & $95.98 \%$ & $0.82(0.72-0.92)$ & $99.38 \%$ & $0.97(0.93-1.00)$ & $96.28 \%$ & $0.85(0.76-0.94)$ \\
\hline Denial & 9 & $22.50 \%$ & $9.38 \%$ & $98.76 \%$ & $0.81(0.63-0.99)$ & $100.00 \%$ & $1.00(\mathrm{~N} / \mathrm{A})$ & $98.76 \%$ & $0.81(0.63-0.99)$ \\
\hline $\begin{array}{l}\text { Non- } \\
\text { disclosure }\end{array}$ & 3 & $7.50 \%$ & $3.12 \%$ & $100.00 \%$ & $1.00(\mathrm{~N} / \mathrm{A})$ & $100.00 \%$ & $1.00(\mathrm{~N} / \mathrm{A})$ & $100.00 \%$ & $1.00(\mathrm{~N} / \mathrm{A})$ \\
\hline $\begin{array}{l}\text { Assumed } \\
\text { NSJ }\end{array}$ & 9 & $22.50 \%$ & $9.38 \%$ & $99.69 \%$ & $0.95(0.84-1.00)$ & $100.00 \%$ & $1.00(\mathrm{~N} / \mathrm{A})$ & $99.69 \%$ & $0.95(0.84-1.00)$ \\
\hline $\mathrm{FD} / \mathrm{SST}$ & 19 & $47.50 \%$ & $19.79 \%$ & $97.52 \%$ & $0.75(0.58-0.94)$ & $99.38 \%$ & $0.94(0.86-1.00)$ & $98.14 \%$ & $0.82(0.68-0.96)$ \\
\hline Any stigma & 96 & - & $100.00 \%$ & $94.43 \%$ & $0.87(0.81-0.93)$ & $99.07 \%$ & $0.98(0.95-1.00)$ & $95.36 \%$ & $0.89(0.84-0.95)$ \\
\hline
\end{tabular}

Note. Equal amount of agreements could result in different $\kappa$ coefficients depending on the base rate of any given category and the distribution of disagreements. All coefficients are significant at $p \leq .001$. Agree - agreement; $\mathrm{Cl}$ - confidence interval; $\kappa$ - kappa coefficient;

$f$ - frequency; SST - social stereotypes; E/R/D - exclusion/rejection/discrimination; MA - micro-aggressions; NSJ - negative social judgment; FD/SST - feeling different/self-stereotyping; N/A - asymptotic standard error equals 0. 
being in their company, label them publicly as "diabetics", segregate them during meals, accuse them unfairly to cause them harm because of T1D or its selfcare, or treat the subject of diabetes as a taboo. This category includes situations in which others compromise the participant's basic interests, and the social attention/inclusion they deserve, because of T1D.

...sometimes they treat me differently, which I don't like... They tell me I can't have something and they give it to someone else... (Girl C, 15)

Gladys CrespoRamos, Eduardo CumbaAvilés, Martha QuilesJiménez

(My friends) always try not to see me testing my glucose or taking out the insulin pump; they say they don't like to look because they feel strange or afraid. (Girl D, 15)

There have been, now and then, professionals who do not take into account the condition; they still consider it a taboo. (Boy D, 13)

Micro-Aggressions. This category entails instances in which others communicate or express to the person hostile, derogatory, passive-aggressive, or patronizing subtle attacks by means of words, gestures or behaviors, whether intentional or not (e.g., calling names, making jokes, feeling pity, being looked at oddly, or being annoyed/bullied because of T1D). It also includes when others display a behavioral pattern suggesting mistrust or vigilance, but lacking enough evidence that its purpose or result are to blame/judge or shame the adolescent.

They treat me bad, they call me 'a junkie' (because of insulin shots). (Girl E, 13)

(It bothers me) When they eat sweets and make fun of me. (Girl A, 13)

The endocrinologist tells me I'm going to die; he traumatizes me. (Girl C, 15)

Many make jokes about my condition and ... because of having the insulin pump, they call me a 'terrorist'. (Boy E, 15)

Most SS reports were related to peers (24) and family (15). Nine were linked with professionals and eight to other figures (i.e., teachers, school diner personnel or "people").

\section{EXAMPLES OF EXPERIENCES OF INTERNALIZED STIGMA}

This global label includes any instance of self-stigmatization whether its focus relates to psychological/emotional, physical, spiritual, or a combination of aspects of the self. In IS, the acceptance or fear of negative social stereotypes about people with diabetes is implicit.

Denial. This category reflects instances in which youths do not accept their condition or express no interest in self-care or open hatred toward all or part of the T1D self-care regimen.

I've never wanted to accept I have T1D, so I don't practice good self-care... (Girl F, 15)

...I hate having to eat at a specific time. (Boy F, 13)

Finally, to get insulin: how I hate it. (Boy G, 16)
When eating too much without injecting myself, I felt I did not have diabetes. (Girl G, 17)

Non-Disclosure. It is coded when the person expresses to others that he/she do not have T1D or omits having the condition, presumably because of anticipated stigma.

I don't have many friends, but those I have, ignore that I'm "diabetic". (Boy H, 17)

(I worry about) how my friends will take it. (Boy I, 13)

Assumed Negative Social fudgment. It refers to youth anticipated fear or expectation of any form of SS towards them or any future offspring, because of having T1D. For instance, some feared to have children because they might present T1D or avoid performing self-care in public because of their fear of facing SS. This category includes the act of ignoring or refusing to hear others' opinions or advice because of the fear of being scolded, rejected or otherwise stigmatized.

(I worry) about having to get insulin at school. (Boy J, 13)

(I fear) that I will lose my eyesight, and that I will gain weight or lose too much! And that people would make fun of me! (Girl C, 15)

(I worry about) having children because I've always been afraid of my children having diabetes. (Girl D, 15)

Feeling Different/Self-Stereotyping. It covers instances in which youths state that they are not like others, perceive themselves as a burden, as weak or inferior, feel incapable of having a "normal" life, of meeting their goals or controlling their impulses, or believe they are absolutely unable to eat sweets or other foods in any circumstances, because of having T1D.

Well, sometimes I feel like an additional responsibility burden... (Boy G, 16)

I cannot eat like a normal girl: sweets, candy, lollipops and different things. (Girl H, 15)

What worries me the most is that... at times I do not feel the same as others. (Girl I, 16)

The most common IS type was Feeling Different/ Self-Stereotyping. Youths internalized society's extreme ideas about their intake of food (e.g., sweets). The rest of this sub-category of IS experiences were mostly about social-related worries or problems accepting T1D or its self-care regimen.

\section{DISCUSSION}

DRS among T1D Latino youth was more common than expected. More than two thirds of them gave responses reflecting some form of DRS. This proportion was higher than those reported in qualitative studies with adults, but quite similar to the one reported by Brazeau et al. (2018) among T1D young people. Nearly half of our sample showed evidence of exposure to SS and of having experienced IS, with over $30.00 \%$ showing both types of stigma and over $38.00 \%$ reporting two 
or more instances of any kind of DRS. As expected, peers were the main source of DRS. As in Browne et al.'s (2013) study, healthcare professionals were a less frequent source of stigma. By examining general and specific types of DRS, this study provides a more detailed profile about the extent of this phenomenon than any previous research with T1D or T2D samples. Ours is also the first published study examining DRS in an exclusively Latino or adolescent sample with T1D. Furthermore, our results are very well supported by the inter-rater reliability data provided.

Some may argue that the high rates of stigma in this sample relate in part to the fact that youth also presented depressive symptoms. Studies have reported a hostile environment and a social rejecting response to individuals with depression, suggesting that this may play an important role in the maintenance of depressed behavior (Coyne, 1976). These symptoms may include having a negative selfimage and decreased social behavior/participation, and might reinforce other IS behaviors such as nondisclosure and denial to avoid the anticipated negative social judgment. Still, we phrased questions in the ADREW to instruct adolescents that their reports should focus on diabetes-related concerns/difficulties and situations/issues that bothered them while interacting with others but that arose specifically because of their status as people with diabetes. Yet, because SS is often reflected as social rejection and the latter is linked to emotional problems, the onset and progression of depression in T1D patients may exacerbate the negative impact of DRS on the person relationships and social roles, with a potential to increase the frequency or intensity of difficulties with peers and family (Nishio \& Chujo, 2017).

However, it is uncertain to what extent sociocultural factors may have influenced the rate of DRS observed in this study. For instance, diabetes-related literacy is relatively low among Puerto Ricans, particularly in the general population (Osborn et al., 2010). There are many myths such as the belief that T1D is caused by the consumption of high-sugar foods. Many ignore the distinction between T1D and T2D. It is, thus, common to blame people with diabetes for their condition and to ignore that some T1D self-care activities (e.g., insulin use) are a life or death matter. This health-related literacy deficiency may explain in part the negative attitudes toward diabetes self-care observed among Latinos (Carbone, Rosal, Torres, Goins, \& Bermudez, 2007; Osborn et al., 2010), which may reflect patients' difficulties accepting their condition as part of their identity. Also, SS and IS among Latinos may be reinforced by the cultural perception of patients with diabetes as weak, sick, vulnerable, and condemned to die sooner than other people (Hart-Kepler, 2017). Systematic and coordinated educational efforts at community, school, and mass media levels to target the stigma related to chronic illness are scarce in Puerto Rico, exposing patients to diverse social stereotypes (e.g., "Diabetes complications are inevitable") and to the internalization of such stereotypes. Although the fatalism attributed to the Hispanic culture has been connected to internalized (e.g., denial) and social stigma (e.g., "Diabetics are doomed"), it is not clear if this is a unique characteristic of this group. Still, some speculate that it may affect Latino people's motivation to learn more about the illness (Caban \& Walker, 2006; Jones \& Crowe, 2017).

Youth in our sample may have been highly exposed to stigma due to the importance that Latinos give to interpersonal relationships. Paradoxically, to be accepted by peers and increase their social support network, youth need to decide whether revealing their health status (opening the door to micro-aggression, blaming, and rejection) is better than avoiding such disclosure, which may put their lives at risk during a severe hypoglycemic episode. Also, Latino culture encourages youth to participate in family and social activities in which food plays an important role. Refusing to eat traditional meals (which may not be a "healthy" option and are served in big portions) could be considered as offensive (desaire) to the host, usually an adult or authority figure, who offers food as a sign of love and care (Cumba-Avilés, 2017). Thus, to show gratitude and keep good relations with relatives (e.g., extended family) and community leaders, youth may need to make exceptions to meal plans that could potentially be "discovered" by parents or siblings, setting the stage for judgment and blame. Some Latino youth in our sample may have been previously exposed to DRS by witnessing the social judgment, blaming and rejection suffered by their relatives living with diabetes, or hearing stories about the complications suffered by those currently dead (Pyatak, Florindez, Peters, \& Weigensberg, 2014). This phenomenon may be more common precisely in populations in which diabetes prevalence is higher (such as among Hispanics). Finally, given the deep economic and debt crisis faced by Puerto Ricans since 2006, and the social perception of diabetes as a complex and expensive illness, some T1D adolescents may have internalized the idea that chronic illness is a burden to family and society in general.

Rates of stigma and number of specific events were unrelated to most socio-demographic variables, with a few exceptions. The finding that youth living in urban zones reported a higher mean total number of stigma events needs further exploration. This mean difference was strongly influenced by SS events. It might be that people in rural zones of Puerto Rico may have a more deeply rooted sense of community, even for disease management, compared to people from urban zones, who may have a more individualistic view of diabetes care. In a study conducted in a rural zone of Kentucky, SS did not emerge as a strong concern or worry, but those with a family
Stigma in Latino youth with $T 1 D$ 
Gladys CrespoRamos,

Eduardo CumbaAvilés, Martha QuilesJiménez history of diabetes were more likely to agree that the community should help those with diabetes managing their condition (Della, 2011). According to Brundisini et al. (2013), although CPI patients from rural zones may feel culturally marginalized in the urban health care context, in rural communities, people may share a feeling of self-reliance and community belonging that may make them more eager to take care of themselves and each other. Similar factors could have possibly contributed to lower SS rates in youth from rural zones in our sample.

On the other hand, adolescents who reported two or more DRS events lived in larger households than those who did not. It is possible that increased family size serves as a factor that promotes opportunities for "home-made" SS (such as blaming or shaming for not reaching self-care goals and exclusion or microaggressions at meals), but also for IS. Youths living at homes with more relatives may be more prone to internalize judgments, labeling, micro-aggressions, and exclusion originated or supported by their relatives because they might perceive them as trusty, loved, and respected figures ("If they all say so, it must be true").

Micro-aggressions accounted for almost half of the SS events reported by youths, while feeling different/ self-stereotyping was the main form of IS. Vishwanath (2014) used the attribution theory to understand the public's stigmatizing views of young people with diabetes. The findings suggest that a large percentage of people misattribute the causes of the disease, believe it is relatively rare, and assume that youths are personally responsible for contracting it. According to this author, "individuals often utilize pejorative terms describing juvenile diabetes as a disease afflicting children who are lazy, unhealthy, fat, obese, lacking exercise, and having eating disorders" (p. 516). Using these terms in reference to youths with diabetes is clearly an expression of SS that may also increase rates of IS, not only when used by adults in the family, but also when used by peers and other authority figures (e.g., healthcare professionals and teachers).

As expected, stigma among T1D Latino youth was related to higher depressive symptoms, particularly anhedonia, and higher odds of presenting a depressive disorder. Given that depression itself is related to poorer self-care and glycemic control, efforts to reduce DRS may contribute directly and indirectly to enhancing health and quality of life in this population. The high rate of depressive symptoms (up to $45.50 \%)$ reported in samples of T1D Latino youth from Puerto Rico (Rivera, González-Nieves, Vélez, \& Colón de Martí, 2007; Rosselló \& Jiménez, 2007), and findings from this study, should encourage policy makers and health care providers in Puerto Rico to work together in developing and applying psychosocial interventions to target DRS and depression among this population and to enhance diabetes-related education in the community using evidencebased approaches.

It is relevant to examine the extent and nature of DRS because many studies evidence its impact on wellbeing and healthcare in people with T1D or T2D (Abdoli et al., 2013a; Browne et al., 2013, 2014; Schabert et al., 2013). According to Lee et al. (2015), those who had experienced stigma also had higher median hospitalizations and poorer glycemic control. Liu et al. (2017) found that among those who were most prone to report that diabetes comes with stigma were patients with higher BMI and the worst glycemic control. The fear of revealing their condition leads patients to hide their disease and to poor treatment adherence (Adams \& Carter, 2010; Alzubaidi et al., 2015). Moreover, anticipated stigma from friends, family, and professionals is associated with decreased quality of life (Earnshaw, 2011). In sum, studies have shown a negative spiral of psychological stigma connected to physical, social and spiritual stigma. This spiral reduces self-care and increases blood glucose and HbA1c levels (Nishio \& Chujo, 2017).

Our results are consistent with previous research in many ways. Similar to our findings, Adams and Carter (2010) reported that denial and fear of stigma were among patient factors causing barriers to an ideal outcome. Other DRS factors found in our Latino youths and reported in previous research include feeling deprived of a normal life and blamed for their condition. Case studies suggest that the development of youths with diabetes and their transition to adulthood could be overshadowed by the emergence of a diabetic identity and the rejection of such identity (Tilden, Charman, Sharples, \& Fosbury, 2005). Also, in a previous qualitative study Hatred of Insulin and Social Outcast were reported as stigma categories emerging among T1D adults (Nishio \& Chujo, 2017), consistent with the Denial and Exclusion/Rejection/ Discrimination categories in our study. Our study suggests that DRS is common even among youths using an insulin pump, confirming that this type of treatment (even if it increases quality of life) may not protect against stigma (Whittaker, 2012). In fact, we found that youth who had insulin pumps reported SS $\left(71.43 \%\right.$ vs. $\left.43.14 \% ; \chi^{2}=3.52, p=.061\right)$ and both types of DRS ( $50.00 \%$ vs. $\left.25.49 \% ; \chi^{2}=3.10, p=.078\right)$ in a marginally higher proportion than those who did not. Our work also supports the link previously found between DRS and depression (Gredig \& Bartelsen-Raemy, 2017), extending its scope to Latino youth.

\section{LIMITATIONS}

Our study has several limitations. Firstly, as all participants had depressive symptoms, their DRS experi- 
ences might have been different from those who do not or those with different psychiatric symptoms. Future efforts should explore DRS among youth with anxiety symptoms, behavior problems, symptoms of eating disorders or no symptoms at all. Second, all assessments were conducted at our clinic. Although we recruited youth from rural and urban zones as well as from metropolitan and non-metropolitan areas, some may have had limited opportunities for participation because of long distances to the clinic (e.g., youths from the western coast of the island). Third, because of the treatment study context, some adolescents might have seen the research evaluators as therapists, which could also have affected their narratives and reporting of some DRS experiences (e.g., experiences related to healthcare professionals). Finally, as the ADREW was not designed for exclusively collecting data about DRS, contrary to Browne et al. (2013), we lacked ways to assess the importance of mass media and other macro-social factors as possible sources of stigma. Future research with T1D Latino youth should use and combine other qualitative (e.g., focus groups or in-depth interviews) and quantitative strategies (e.g., structured questionnaires) for data collection, including questions addressing mass media, cultural and macro-social factors. In spite of these limitations, this study represents a preliminary effort that may significantly contribute to gaining a deeper understanding of how stigmatization processes affect Latino adolescents living with T1D in Puerto Rico, and its relationship with depressive symptoms.

\section{IMPLICATIONS AND FUTURE DIRECTIONS}

Our results have implications for healthcare professionals who work with T1D youth. It is essential that they consider the relational aspects of DRS. For instance, mental health workers should explore how SS processes have affected the person, as they would do with any other aspect of their developmental history, to understand whether in any case they are related to particular symptoms. As argued by Nishio and Chujo (2017), "it is important for nurses to assess patients from various viewpoints, including the viewpoint of stigma” (p. 167). Furthermore, it is vital that all professionals be aware of their views about T1D and those who live with it to avoid reproducing prejudice and stereotypes during the service providing process. The latter should focus on treating patients as a whole person and with respect, in order to increase the quality of the relationship, since a dismissive patient attachment and poor patient-provider communication may be related to worse treatment adherence and glycemic control (Ciechanowski, Katon, Russo, \& Walker, 2001).
There is a need for advancing a research agenda to address the manifestations and impact of DRS among youth in multiple contexts and scenarios. Accordingly, we propose that future efforts address these topics: 1) the impact of SS and IS in youths' treatment adherence, global functioning, and health (including relational, physical, emotional, and spiritual aspects); 2) the rates, nature, and impact of stigma among relatives of T1D adolescents; 3) levels of diabetes knowledge among the general population and healthcare professionals, and their relationship with stigma-related behaviors and attitudes; 4) the diverse aspects of structural and social media stigmatization of Latino people living with diabetes; 5) similarities and differences in the extent, nature and impact of DRS among young people with T1D vs. T2D; and 6) the assessment of the DRS management strategies used by Latinos living with these conditions. The knowledge generated through this research agenda would serve as a platform to develop culturally relevant (clinical and educational) DRS reduction interventions, whose effectiveness should be assessed at individual and community-based levels. By examining the extent and characterizing the nature of DRS among T1D Latino youth from Puerto Rico, our study is an important step in that direction.

\section{ACKNOWLEDGEMENTS}

The authors would like to thank Dr. Patricia GarcíaDíaz (first Project Coordinator), and all the research assistants who collaborated in this study. We are particularly grateful to the Pediatric Diabetes Foundation and the Committee for the Education and Wellbeing of Children and Adolescents with Diabetes (CEBNAD, by its Spanish acronym).

\section{References}

Abdoli, S., Abazari, P., \& Mardanian, L. (2013a). Exploring diabetes type 1-related stigma. Iranian Journal of Nursing and Midwifery Research, 18, 65-70.

Abdoli, S., Irani, M. D., Parvizi, S., Fatemi, N. S., \& Amini, M. (2013b). Living in the shadow and light: Iranian youths' responses to diabetes-related stigma. European Online Journal of Natural and Social Sciences, 2, 439-448.

Adams, O. P., \& Carter, A. O. (2010). Diabetes and hypertension guidelines and the primary health care practitioner in Barbados: knowledge, attitudes, practices and barriers: a focus group study. BMC Family Practice, 11, 96-96. https://doi. org/10.1186/1471-2296-11-96

Alzubaidi, H., Mc Mamara, K., Chapman, C., Stevenson, V., \& Marriott, J. (2015). Medicine-taking experiences and associated factors: comparison between
Stigma in Latino youth with $T 1 D$ 
Arabic-speaking and Caucasian English-speaking patients with type 2 diabetes. Diabetic Medicine: A Journal of the British Diabetic Association, 32, 1625-1633. https://doi.org/10.1111/dme.12751

Banion, C. R., Miles, M. S., \& Carter, M. C. (1983). Problems of mothers in management of children with diabetes. Diabetes Care, 6, 548-551.

Bossy, D., Knutsen, I. R., Rogers, A., \& Foss, C. (2017). Group affiliation in self-management: support or threat to identity? Health Expectations, 20, 159170. https://doi.org/10./hex. 12448

Gladys CrespoRamos,

Eduardo CumbaAvilés, Martha QuilesJiménez

Bravo, M., Ribera, J., Rubio-Stipec, M., Canino, G., Shrout, P., Ramírez, R., Fábregas, L., Chavez, L., Alegría, M., Bauermeister, J. J., \& Taboas, A. M. (2001). Test-retest reliability of the Spanish version of the Diagnostic Interview Schedule for Children (DISC-IV). Journal of Abnormal Child Psychology, 29, 433-444. https://doi.org/10.1023/A:1010499520090

Brazeau, A.-S., Nakhla, M., Wright, M., Henderson, M., Panagiotopoulos, C., Pacaud, D., Kearns, P., Rahme, E., Da Costa, D., \& Dasgupta, K. (2018). Stigma and its association with glycemic control and hypoglycemia in adolescents and young adults with type 1 diabetes: Cross-sectional study. Journal of Medical Internet Research, 20, e151. https://doi. org/10.2196/jmir.9432

Browne, J. L., Ventura, A., Mosely, K., \& Speight, J. (2013). 'I call it the blame and shame disease': a qualitative study about perceptions of social stigma surrounding type 2 diabetes. BMJ Open, 3, e003384-e003384. https://doi.org/10.1136/bmjopen-2013-003384

Browne, J. L., Ventura, A., Mosely, K., \& Speight, J. (2014). 'I'm not a druggie, I'm just a diabetic': a qualitative study of stigma from the perspective of adults with type 1 diabetes. BMJ Open, 4, e005625-e005625. https://doi.org/10.1136/bmjopen-2014-005625

Brundisini, F., Giacomini, M., Dejean, D., Vanstone, M., Winsor, S., \& Smith, A. (2013). Chronic disease patients' experiences with accessing health care in rural and remote areas: a systematic review and qualitative meta-synthesis. Ontario Health Technology Assessment Series, 13, 1-33. Available from http://www.hqontario.ca/en/ documents/ eds/2013/full-report-OCDM-rural-health-care.pdf.

Caban, A., \& Walker, E. A. (2006). A systematic review of research on culturally relevant issues for Hispanics with diabetes. The Diabetes Educator, 32, 584595. https://doi.org/10.1177/0145721706290435

Cabassa, L. J., Hansen, M. C., Palinkas, L. A., \& Ell, K. (2008). Azúcar y nervios: Explanatory models and treatment experiences of Hispanics with diabetes and depression. Social Science \& Medicine, 66, 24132424. https://doi.org/10.1016/j.socscimed.2008.01.054

Carbone, E. T., Rosal, M. C., Torres, M. I., Goins, K. V., \& Bermudez, O. I. (2007). Diabetes self-management: Perspectives of Latino patients and their health care providers. Patient Education and Counseling, 66, 202210. https://doi.org/10.1016/j.pec.2006.12.003

Centers for Disease Control and Prevention. (2016). Chronic Disease Indicators (CDI) Data. Retrieved from http://nccd.cdc.gov/cdi

Ciechanowski, P. S., Katon, W. J., Russo, J. E., \& Walker, E. A. (2001). The patient-provider relationship: Attachment theory and adherence to treatment in diabetes. American Journal of Psychiatry, 158, 29-35. https://doi.org/10.1176/appi.ajp.158.1.29

Clarke, J., Vatiliotis, V., Verge, C. F., Holmes-Walker, J., Campbell, L. V., Wilhelm, K., \& Proudfoot, J. (2015). A mobile phone and web-based intervention for improving mental well-being in young people with type 1 diabetes: design of a randomized controlled trial. JMIR Research Protocols, 4, e50. https://doi. org/10.2196/resprot.4032

Commissariat, P. V., Kenowitz, J. R., Trast, J., Heptulla, R. A., \& Gonzalez, J. S. (2016). Developing a personal and social identity with type 1 diabetes during adolescence: A hypothesis generative study. Qualitative Health Research, 26, 672-684. https://doi.org/10.1177/1049732316628835

Coyne, J. C. (1976). Depression and the response of others. Journal of Abnormal Psychology, 85, 186193. https://doi.org/10.1037/0021-843x.85.2.186

Cumba-Avilés, E. (2017). Cognitive-behavioral group therapy for Latino youth with type 1 diabetes and depression: A case study. Clinical Case Studies, 16, 58-75. https://doi.org/10.1177/1534650116668270

Cumba-Avilés, E., \& Sáez-Santiago, E. (2016). Research program on type 1 diabetes and youth depression in Puerto Rico. Revista Puertorriqueña de Psicología, 27, 44-60.

Della, L. J. (2011). Exploring diabetes beliefs in at risk Appalachia. The Journal of Rural Health, 27, 3-12. https://doi.org/10.1111/j.1748-0361.2010.00311.x

Della, L. J., Ashlock, M. Z., \& Basta, T. B. (2011). Social construction of diabetes-related stigma in Appalachia: Implications for local public health officials. Paper presented at the American Public Health Association 139th Annual Meeting and Exposition, Washington, DC.

Earnshaw, V. A. (2011). Chronic illness and anticipated stigma. (Dissertation), University of Connecticut. Retrieved from https://opencommons.uconn.edu/ dissertations/ AAI3485227

Earnshaw, V. A., \& Quinn, D. M. (2012). The impact of stigma in healthcare on people living with chronic illnesses. Journl of Health Psychology, 17, 157-168. https://doi.org/10.1177/1359105311414952

Elissa, K., Bratt, E. L., Axelsson, A. B., Khatib, S., \& Sparud-Lundin, C. (2017). Societal norms and conditions and their influence on daily life in children with type 1 diabetes in the West Bank in Palestine. Journal of Pediatric Nursing, 33, 16-22. https://doi.org/10./j.pedn.2016.12.005

Fischer, A. E. (1948). Factors responsible for emotional disturbances in diabetic children. Nervous Child, 7, 78-83. 
Folias, A. E., Brown, A. S., Carvalho, J., Wu, V., Close, K. L., \& Wood, R. (2014). Investigation of the Presence and Impact of Social Stigma on Patients with Diabetes in the USA. Paper presented at the 74th American Diabetes Association Annual Convention, Boston, MA.

Goffman, E. (1963). Stigma: notes on the management of spoiled identity. Englewood Cliffs, NJ: Prentice-Hall.

Gray, A. J. (2002). Stigma in psychiatry. Journal of the Royal Society of Medicine, 95, 72-76.

Gredig, D., \& Bartelsen-Raemy, A. (2017). Diabetesrelated stigma affects the quality of life of people living with diabetes mellitus in Switzerland: implications for healthcare providers. Health \& Social Care in the Community, 25, 1620-1633. https:// doi.org/10.1111/hsc. 12376

Hansen, M. C., \& Cabassa, L. J. (2012). Pathways to depression care: help-seeking experiences of low-income Latinos with diabetes and depression. Journal of Immigrant and Minority Health, 14, 1097-1106. https://doi.org/10.1007/s10903-012-9590-x

Hapunda, G., Abubakar, A., van de Vijver, F., \& Pouwer, F. (2015). Living with type 1 diabetes is challenging for Zambian adolescents: qualitative data on stress, coping with stress and quality of care and life. BMC Endocrine Disorders, 15, 20-20. https://doi.org/10.1186/s12902-015-0013-6

Hart-Kepler, V. L. (2017). Mexican-Born Immigrant Decision-Making About Self-Management of Type 2 Diabetes. (Doctoral dissertation), University of San Diego. Retrieved from http://digital.sandiego. edu/dissertations $/ 88$

Haugvik, S., Beran, D., Klassen, P., Hussain, A., \& Haaland, A. (2017). "My heart burns" - A qualitative study of perceptions and experiences of type 1 diabetes among children and youths in Tajikistan. Chronic Illness, 13, 128-139. https://doi.org/10./1742395316668566

Jacoby, A. (1994). Felt versus enacted stigma: a concept revisited. Evidence from a study of people with epilepsy in remission. Social Science and Medicine, 38, 269-274. https://doi.org/10.1016/02779536(94)90396-4

Jones, V., \& Crowe, M. (2017). How people from ethnic minorities describe their experiences of managing type-2 diabetes mellitus: A qualitative meta-synthesis. International Journal of Nursing Studies, 76, 78-91. https://doi.org/10.1016/j.ijnurstu.2017.08.016

Kato, A., Fujimaki, Y., Fujimori, S., Izumida, Y., Suzuki, R., Ueki, K., Kadowaki, T., \& Hashimoto, H. (2016). A qualitative study on the impact of internalized stigma on type 2 diabetes self-management. Patient Education and Counseling, 99, 12331239. https://doi.org/10.1016/j.pec.2016.02.002

Kato, A., Takada, M., \& Hashimoto, H. (2014). Reliability and validity of the Japanese version of the self-stigma scale in patients with type 2 diabetes. Health And Quality Of Life Outcomes, 12, 179-179. https://doi.org/10.1186/s12955-014-0179-z
Kovacs, M. (2001). Children's Depression Inventory (CDI): Technical Manual. North Tonawanda, NY: Multi-Health Systems.

Lambert, V., \& Keogh, D. (2015). Striving to live a normal life: a review of children and young people's experience of feeling different when living with a long term condition. Journal of Pediatric Nursing, 30, 63-77. https://doi.org/10./j.pedn.2014.09.016

Lee, S., Lee, M. T.Y., Chiu, M. Y. L., \& Kleinman, A. (2005). Experience of social stigma by people with schizophrenia in Hong Kong. The British Journal of Psychiatry, 186, 153-157. https://doi.org/10.1192/bjp.186.2.153

Lee, S. M., Lim, L. C., \& Koh, D. (2015). Stigma among workers attending a hospital specialist diabetes clinic. Occupational Medicine, 65, 67-71. doi: 10.1093/occmed/kqu 150

Liu, N. F., Brown, A. S., Younge, M. F., Guzman, S. J., Close, K. L., \& Wood, R. (2017). Stigma in people with type 1 or type 2 diabetes. Clinical Diabetes, 35, 27-34. https://doi.org/10.2337/cd16-0020

Llorente, M. D., \& Malphrus, J. E. (Eds.) (2007). Psychiatric disorders and diabetes mellitus. Oxon, UK: Informa Healthcare.

Marshall, M., Carter, B., Rose, K., \& Brotherton, A. (2009). Living with type 1 diabetes: perceptions of children and their parents. Journal of Clinical Nursing, 18, 1703-1710.

McQuillan, L. (2014). Latinos and Hispanics and diabetes: The need for outreach. Insulin Nation. Retrieved from http://insulinnation.com/living/ latinos-and-diabetes-the-need-for-outreach/

Mulvaney, S. A., Hood, K. K., Schlundt, D. G., Osborn, C. Y., Johnson, K. B., Rothman, R. L., \& Wallston, K. A. (2011). Development and initial validation of the barriers to diabetes adherence measure for adolescents. Diabetes Research and Clinical Practice, 94, 77-83. https://doi.org/10.1016/j.diabres.2011.06.010

Muze, K. C., \& Majaliwa, E. S. (2015). Type 1 diabetes care updates: Tanzania. Indian Journal of Endocrinology and Metabolism, 19, S12-S13. https://doi. org/10.4103/2230-8210.155348

NCD Risk Factor Collaboration. (2016). Worldwide trends in diabetes since 1980: a pooled analysis of 751 population-based studies with 4.4 million participants. The Lancet, 387, 1513-1530. https:// doi.org/10.1016/S0140-6736(16)00618-8

Nishio, I., \& Chujo, M. (2017). Self-stigma of patients with type 1 diabetes and their coping strategies. Yonago Acta Medica, 60, 167-173. Available from http://www.lib.tottori-u.ac.jp/yam/yam/yam60-3/ yam-60-167.pdf

O’Donohue, W. T., \& Tolle, L. W. (2009). Behavioral approaches to chronic disease in adolescence: A guide to integrative care. New York, NY: Springer.

Osborn, C. Y., Amico, K. R., Cruz, N., O'Connell, A. A., Perez-Escamilla, R., Kalichman, S. C., Wolf, S. A. \& Fisher, J. D. (2010). A brief culturally tailored intervention for Puerto Ricans with type 2 diabetes.
Stigma in Latino youth with $T 1 D$ 
Health Education and Behavior, 37, 849-862. https://doi.org/10.1177/1090198110366004

Piette, J. D., \& Kerr, E. A. (2006). The impact of $\mathrm{co}^{-}$ morbid chronic conditions on diabetes care. Diabetes Care, 29, 725-731. https://doi.org/10.2337/ diacare.29.03.06.dc05-2078

Pyatak, E. A., Florindez, D., Peters, A. L., \& Weigensberg, M. J. (2014). "We Are All Gonna Get Diabetic These Days": The Impact of a Living Legacy of Type 2 Diabetes on Hispanic Young Adults' Diabetes Care. Diabetes Educator, 40, 648-658. https:// doi.org/10.1177/0145721714535994

Ramos,

Eduardo CumbaAvilés,

Martha QuilesJiménez

Rankin, D., Harden, J., Jepson, R., \& Lawton, J. (2017). Children's experiences of managing type 1 diabetes in everyday life: a thematic synthesis of qualitative studies. Diabetic Medicine, 34, 1050-1060. https://doi.org/10.1111/dme.13362

Rivera, A., González-Nieves, M. I., Vélez, N., \& Colón de Martí, L. N. (2007). Indicadores de síntomas depresivos en una muestra de jóvenes de 12 a 17 años de edad con diabetes tipo 1 [Indicators of depressive symptoms in a sample of youth aged 12 to 17 years with type 1 diabetes mellitus]. Puerto Rico Health Science Journal, 26, 51-56.

Rosselló, J., \& Jiménez-Chafey, M. I. (2007). Depressive and anxious symptomatology in Puerto Rican youth with type 1 diabetes mellitus and their relationship to glycemic control. Ciencias de la Conducta, 22, 103-126.

Rosselló, J., \& Maysonet-Guzmán, M. (2006). Dificultades y preocupaciones identificadas por jóvenes puertorriqueños/as con diabetes mellitus insunodependientes (IDDM): Su relación con control metabólico, desesperanza, apoyo social y sintomatología depresiva [Difficulties and worries identified by Puerto Rican youth with insulin-dependent diabetes mellitus (IDDM): Their relationship with metabolic control, hopelessness, social support, and depressive symptomatology]. Puerto Rico Health Sciences Journal, 5, 331-335.

Sayles, J. N., Ryan, G. W., Silver, J. S., Sarkisian, C. A., \& Cunningham, W. E. (2007). Experiences of social stigma and implications for healthcare among a diverse population of HIV positive adults. Journal of Urban Health, 84, 814-828. https://doi. org/10.1007/s11524-007-9220-4

Scambler, G. (1998). Stigma and disease: changing paradigms. Lancet, 352, 1054-1055. https://doi. org/10.1016/s0140-6736(98)08068-4

Schabert, J., Browne, J. L., Mosely, K., \& Speight, J. (2013). Social stigma in diabetes: A framework to understand a growing problem for an increasing epidemic. The Patient: Patient-Centered Outcomes Research, 6, 1-10. https://doi.org/10.1007/s40271012-0001-0

Shaffer, D., Lucas, C. P., Dulcan, M. K., \& SchwabStone, M. E. (2000). NIMH Diagnostic Interview Schedule for Children Version IV (NIMH DISC-IV):
Description, differences from previous versions, and reliability of some common diagnoses. Journal of the American Academy of Child Adolescent Psychiatry, 39, 28-38.

Stokes, A., \& Preston, S. H. (2017). Deaths attributable to diabetes in the United States: Comparison of data sources and estimation approaches. PLOS ONE, 12, e0170219. https://doi.org/10./journal.pone.0170219

Tak-Ying Shiu, A., Kwan, J. J. Y.-M., \& Wong, R. Y.-M. (2003). Social stigma as a barrier to diabetes selfmanagement: implications for multi-level interventions. Journal of Clinical Nursing, 12, 149-150. https://doi.org/10.1046/j.1365-2702.2003.00735.x

Tilden, B., Charman, D., Sharples, J., \& Fosbury, J. (2005). Identity and adherence in a diabetes patient: Transformations in psychotherapy. Qualitative Health Research, 15, 312-324. https://doi. org/10.1177/1049732304272965

Vaz, M., Travasso, S. M., \& Vaz, M. (2016). Perceptions of stigma among medical and nursing students and tuberculosis and diabetes patients at a teaching hospital in southern India. Indian Journal of Medical Ethics, 1, 8-16. https://doi.org/10.20529/ IJME.2016.003

Vishwanath, A. (2014). Negative public perceptions of juvenile diabetics: Applying attribution theory to understand the public's stigmatizing views. Health Communication, 29, 516-526. https://doi.org/ 10.1080/10410236.2013.777685

Weiler, D. M., \& Crist, J. D. (2009). Diabetes self-management in a Latino social environment. Diabetes $E d-$ ucator, 35, 285-292. doi: 10.1177/0145721708329545

Whittaker, J. A. (2012). The effect of insulin pump therapy on children and adolescents' quality of life: A qualitative study. (Doctoral dissertation), University of Glasgow.

Willig, A. L., Richardson, B. S., Agne, A., \& Cherrington, A. (2014). Intuitive eating practices among African-American women living with type 2 diabetes: a qualitative study. Journal of the Academy of Nutrition and Dietetics, 114, 889-896. 